\title{
LA TOLERANCIA DEL PROGRESISMO MODERNO COMO UN ACERCAMIENTO A LA PERFECTIBILIDAD
}

\section{THE TOLERANCE OF MODERN PROGRESSIVISM AS AN APROACH TO PERFECTIBILITY}

\author{
Lukas Echegaray ${ }^{1}$ \\ Universidad de Los Andes, Chile
}

\begin{abstract}
Resumen: El progresismo moderno se esmera por garantizar las libertades individuales junto con la libertad de conciencia y el reconocimiento de la opinión de todos los individuos. Este mundo de carácter omnicomprensivo es posible mediante un modo de la tolerancia que respete la autonomía de cada uno. En efecto, según esta perspectiva, la humanidad progresa al garantizar que cada individuo persiga sus propios intereses. Con todo, este optimismo ante la libertad peligra en caer en una actitud de indiferencia, ya que se fundamenta en una visión individualista de la perfección humana. Ante esto, se abordará la posibilidad de una virtud de la tolerancia que trascienda el mero no-intervencionismo, y que tenga como propósito la integridad del individuo. De este modo, la política liberal no consistiría tan solo en la mera neutralidad del modus vivendi, sino también en que las libertades individuales sean bien llevadas por medio de la virtud de la tolerancia.
\end{abstract}

Descriptores: Progresismo · Perfectibilidad · Tolerancia · Autonomía · Indiferencia.

\begin{abstract}
Modern progressivism strives to guarantee individual freedoms along with freedom of conscience and recognition of the opinion of all individuals. This all-understanding world is possible through a mode of tolerance that respects the autonomy of each one. Indeed, according to this perspective, humanity progresses by ensuring that each individual pursues his own interests. However, this optimism about freedom risks falling into an attitude of indifference, since it is based on an individualistic vision of human perfection. Given this, will be expose the possibility of a virtue of tolerance that transcends mere non-interventionism, and whose purpose is the integrity of the individual. In this way, liberal politics would not consist only in the mere neutrality of the modus vivendi, but also in individual liberties being well managed through the virtue of tolerance.
\end{abstract}

Keywords: Progressivism $\cdot$ Perfectibility $\cdot$ Tolerance $\cdot$ Autonomy $\cdot$ Indifference

Enviado: 07/04/2021. Aceptado: 22/05/2021

\footnotetext{
${ }^{1}$ E-mail: lechegaray@uandes.cl
} 


\section{INTRODUCCIÓN}

Los primeros llamados a la libertad de conciencia se originaron en el s. XVII. Las diferencias, tanto religiosas como políticas, entre los distintos reinos de Europa Central acarrearon un período de guerras que perduró varias décadas. La persecución y el conflicto religioso alabados por los mismos regímenes políticos, ${ }^{2}$ obligaron a que pensadores de la época como Baruch Spinoza, Sebastián Castellio y John Locke (entre otros) exigieran la libertad de elegir libremente su propia religión sin la imposición de la autoridad política. ${ }^{3}$ Aquello posibilitó una teoría política que reduce el rol del Estado, que garantiza las libertades individuales. ${ }^{4}$

Este vuelco radical de la filosofía política significó también un cambio en la actitud ante la perfectibilidad humana. La filosofía política liberal orientó el propósito de la comunidad política hacia las libertades individuales, en vez de dirigirla a concepciones determinadas del bien. Por ende, el contexto político de la Modernidad origina una teoría política basada en un principio antropológico pesimista, el cual consiste en una concepción egoísta del individuo incapaz de perfeccionarse moralmente por medio de la política.

No obstante, este pesimismo ante la perfectibilidad fue paulatinamente superado. ${ }^{5}$ En El imperio del mal menor, Jean-Claude Michéa retrata cómo las políticas liberales abandonaron el minimalismo y el pesimismo del comienzo de la Modernidad, y se irguieron como "el mejor mundo posible"6 para el hombre: el ciudadano se perfecciona mediante la libertad, no precisamente por exigentes valores morales.

Este cambio en la perspectiva política no ha sido muy considerado por la literatura que trata la tolerancia. El enfoque histórico resulta fundamental para evidenciar el desarrollo de la concepción de la tolerancia e, incluso, especular sobre su verdadero propósito en la sociedad abierta. El origen de este concepto nos recuerda que la libertad de consciencia no emergió por una aspiración inmediata de la libertad individual, sino como reparadora de conflictos. En ese sentido, cabe

\footnotetext{
${ }^{2}$ Rousseau describe de manera acertada la tensión en la estrecha relación entre el poder político y el religioso en aquel siglo: "Por el solo hecho de que se ponía a Dios a la cabeza de cada sociedad política, se sigue que hubo tantos dioses como pueblos. Dos pueblos extraños el uno al otro, y casi siempre enemigos, no pueden reconocer por mucho tiempo a un mismo señor: dos ejércitos que luchan no pueden obedecer al mismo jefe. Así, de las divisiones nacionales resultó el politeísmo, y de allí la intolerancia teológica y civil que, naturalmente, es la misma (...).”Jean-Jacques Rousseau (2003), p. 167.
}

${ }^{3}$ Para abordar el conflicto religioso y el origen de la libertad de conciencia, véase Zagorin (2003).

${ }^{4}$ Cf. John Locke (2010), pp. 11-15.

${ }^{5}$ Para una mayor comprensión sobre la evolución de las actitudes de la teoría política moderna tratadas en este artículo, véase el ensayo de Leo Strauss (1989), pp. 81-98.

${ }^{6}$ Jean Claude Michéa (2009), pp. 138-48. 
preguntarnos por la posibilidad de un modo de la tolerancia que se encamine a sobrellevar el pluralismo de los valores, pero que, a la vez, no se reduzca al mero reconocimiento individual.

En medio del optimismo que describe Michéa, surge la perspectiva progresista de la historia, cuyo propósito final consiste en el reconocimiento y libre desenvolvimiento de las libertades individuales. No obstante, el s. XX se encuentra plagado de conflictos, incluyendo dos Guerras Mundiales, que ponen en duda aquella interpretación progresista. En otras palabras, podemos afirmar la posibilidad del fracaso político y moral de aquella interpretación progresista, de la misma manera que los conflictos de religión acabaron con la filosofía políticoteológica del s. XVII. Por ejemplo, en su reconocida obra La decadencia de Occidente, Spengler nota un pesimismo cultural y moral en las sociedades de Europa en medio de los conflictos del s. XX. Una perspectiva de este tipo es absolutamente válida.

Sin embargo, debemos admitir que ha habido un aumento en las expectativas de la libertad humana, lo que replantea el modelo de las sociedades. Resulta impensable en la democracia liberal actual imponer políticas con exigencias morales, tales como las virtudes de la filosofía política clásica. Pero, a la vez, las sociedades de Occidente se han convertido en comunidades más abiertas y comprensivas ante lo diferente. De alguna manera, esto podría significar un progreso en la convivencia entre los individuos de una comunidad política.

Aquel mundo omnicomprensivo pretendido por el progresismo requiere de una tolerancia que sustituya la ética de la filosofía política clásica y medieval. Ahora bien, mostraremos en este artículo, que el modo de la tolerancia tiene una gran relevancia, ya que puede determinar la relación política entre los individuos. En otras palabras, la tolerancia puede significar no-intervención, neutralidad e indiferencia; pero también esta puede orientarse hacia la integridad y el buen llevar de la autonomía. En ese sentido, la tesis consiste en establecer la posibilidad de una tolerancia con un propósito moral en el progresismo moderno.

En el siguiente artículo, Jean-Claude Michéa nos permitirá abordar el modo en que se desenvuelve el respeto a la autonomía y el aparente optimismo del progresismo, aunque con cierta sospecha y negatividad. De este modo, el respeto, la benevolencia y la hospitalidad no representan nada más que el amor propio, y una actitud que tiene como último propósito la propia libertad. Por ende, esta visión negativa nos ayudará a explorar la posibilidad de una tolerancia fundamentada en el mero individualismo y la indiferencia.

A raíz de lo anterior, es posible encontrar en el liberalismo algunas perspectivas con un enfoque antiperfeccionista, como la teoría clásica de S. 
Mill y la ponderación de los intereses privados sin una concepción mínima de bien común. No obstante, es injusto tratar la política liberal y la tolerancia como sinónimos de indiferencia, relativismo moral o escepticismo. Hay otras perspectivas que intentan salvar la imagen del liberalismo como una política que persigue el bien en general, y no sólo el de cada uno. En el presente artículo, aquel intento será defendido mediante el "modelo moral" de la tolerancia postulado por Anna E. Galeotti, quien intenta distinguir el respeto de la indiferencia. Esta última demostración nos permitiría finalmente establecer una relación entre el respeto a la autonomía y la perfectibilidad humana.

\section{EL OPTIMISMO DEL PROGRESISMO ANTE LA PERFECTIBILIDAD}

Tal como afirmamos en la introducción, las primeras teorías políticas del s. XVII estaban impregnadas de pesimismo ante la perfección moral de los individuos. La filosofía política de Maquiavelo y Hobbes, principalmente, son un ejemplo claro de aquella actitud, la cual denominamos también como realismo político. En otras palabras, las expectativas de la tradición moderna no alcanzan para establecer un orden social dentro de los límites de la moralidad. El orden moral pareciera exceder las capacidades de la naturaleza humana, de tal manera que adquiere un carácter utópico e irreal. ${ }^{7}$ Esto genera una transformación completa de la concepción de la naturaleza humana, en la que el hombre ya no tiende naturalmente a la política (o a ser un animal político), sino que su telos se reduce a la mera sobrevivencia. El renombrado principio antropológico de Hobbes es bastante certero: "el hombre es un lobo para el hombre". 8

No pretendemos entrar en detalles en aquel comienzo de la tradición moderna. Tan solo intentamos advertir el pesimismo de la época, gracias al cual la política liberal adquiere un carácter neutral y un modo de razonar minimalista. Esto se traduce en un Estado que no impone ninguna creencia ni valores determinados, y que se encarga únicamente de proteger los derechos individuales. Ahora bien, aquellas libertades permiten que los propios individuos definan lo mejor para ellos mismos sin la imposición moral del Estado ni de la Iglesia. La disputa por lo moralmente correcto e incorrecto es reemplazada por la libertad de conciencia. Así, se establece un minimalismo que consiste en establecer únicamente los valores necesarios para la mera convivencia entre los individuos. Por consiguiente, el axioma de la neutralidad se define, en principio,

\footnotetext{
${ }^{7}$ Cf. Benedictus de Spinoza (1986), pp. 77-83.

${ }^{8}$ Thomas Hobbes (2009), p. 3.
} 
como una política antiperfeccionista, ya que no hay ninguna pretensión de perfección. En ese sentido, aquel axioma procura tan solo la coexistencia pacífica entre los individuos.

No obstante, este pesimismo de la teoría liberal se convierte en optimismo en una nueva etapa progresista del liberalismo. Hay un cambio de perspectiva en la concepción de la naturaleza humana: los individuos se perfeccionan al perseguir sus intereses privados, ya que la libertad se establece como parámetro perfectible de las intenciones, desplazando a la moral. Por tanto, debido al optimismo en la libertad, la moralidad adquirió un menor protagonismo en el orden social. Incluso, la perspectiva moral y religiosa son consideradas como una perturbación de la libertad individual y el orden público. ${ }^{9}$

Ahora bien, aquel optimismo no se refleja únicamente en el abandono de las disputas morales, sino también en la historia y las ciencias. El mismo lente mediante el que se observa el desarrollo progresivo de la tecnología, ha puesto su enfoque en la historia. A saber, la opinión del hombre moderno en general se caracterizó por considerar la historia como una resolución ante cualquier dificultad, de tal manera que esta obtiene una cualidad salvífica. De esta manera, la cultura humana y sus instituciones adquieren un carácter evolutivo, sin que los hechos y el libre albedrío sean sometidos a una interpretación universal de la historia. Por ende, no hay un significado universal de la historia porque no hay una visión acabada de la misma.

Aquella falta de adecuación entre un significado universal de la historia y los hechos particulares de su proceso puede resultar problemática. ${ }^{10}$ Una preponderancia de los hechos puede afectar a la definición de un orden moral robusto. En aquel caso, la moral se ajustaría al progreso, adquiriendo un carácter minimalista. Por este motivo, R. Song afirma que aquel tipo de perspectivas progresistas desmiembra totalmente la esencia de la humanidad. En otras palabras, ante la falta de definición de un significado universal de la historia,

\footnotetext{
${ }^{9}$ Michéa (2009), p. 62.

${ }^{10}$ Con todo, no hay que olvidar los intentos del idealismo alemán contemporáneo por sintetizar un significado universal de la historia y los hechos que la constituyen. Autores como Hegel y Schelling pretendían establecer una unidad del dualismo necesidad (o trascendencia) y libertad. Estos establecieron ciertos intentos por enraizar ciegamente una visión apriorística de la historia en el libre albedrío de la especie humana, y establecer una continuidad entre los individuos que permita el progreso mediante la razón y libertad. Schelling afirma: “(...) nada de lo que sucede según un mecanismo determinado o tiene su teoría a priori es objeto de la historia. Teoría e historia son totalmente opuestas. El hombre tiene historia solo porque lo que hará no se puede calcular de antemano por ninguna teoría. El albedrío es, en este sentido, el dios de la historia. (...) tampoco merece el nombre de historia lo absolutamente desprovisto de ley, o sea, una serie de acontecimientos sin finalidad ni intención, y que solo la unión de libertad y legalidad o la paulatina realización por toda una especie de seres de un ideal nunca completamente perdido constituye lo propio de la historia." (Schelling, 2005, Sistema del idealismo trascendental, pp. 589-590.)
} 
esta se convierte en la salvadora de la humanidad. ${ }^{11}$ Por consiguiente, no hay una definición de la perfección humana, sino que esta se descubre a medida que la humanidad progresa. ${ }^{12}$

En el caso de la esfera política, ante el optimismo en las ciencias, la teoría en torno al interés privado ha adquirido las características del método científico. Desde el s. XVII, el mundo moderno se ha asombrado del equilibrio de las ciencias positivas, cuyo método imparcial se pretende imitar en el plano político de los intereses de una sociedad: la satisfacción y canalización de las pasiones conducen a la prosperidad pública. ${ }^{13}$

Por tanto, las condiciones sociales del mundo moderno fueron perfectas para la proliferación de una teoría política individualista como la del progresismo. De este modo, la perfección de los individuos radica en aspectos como la historia, la técnica y la ciencia, pero no necesariamente en las virtudes. De la misma manera que el pelagianismo fundamenta la redención en la libertad y en las capacidades naturales del hombre (en lugar de la gracia divina), el progresismo se fía de su impulso egoísta para establecer la armonía social.

Sin embargo, J. Michéa tiene una visión bastante crítica respecto al optimismo del progresismo. En El imperio del mal menor afirma que la obsesión de la política actual por garantizar las libertades individuales pareciera dirigirnos a un inevitable conflicto de todos contra todos, debido a la provocación y resistencia que pueden acarrear estas libertades. Ante ello, la tolerancia surge como una solución evidente para el conflicto. Pero Michéa se pregunta: ¿a qué costo? La pregunta se debe a que a medida que establecemos cada vez más libertades (legalización de las drogas, derecho a portar armas, etc.), estas requieren de una mayor vigilancia, lo que implica cierto control sobre aquellas libertades. Por tanto, pareciera que nos enfrentamos a un mundo

\footnotetext{
${ }^{11}$ Incluso, parte del pensamiento cristiano ha interpretado ciertos procesos de la historia como el mismo Cristo, de tal manera que se pretende buscar la redención en ella. El problema de este tipo de interpretaciones radica en el significado que tendrían los diversos momentos de la historia ante una visión escatológica; ciertas civilizaciones o emperadores representarían la Verdad y la fe de Cristo. ("The concept of religious progress through the birth and death of civilizations has the merit of calling attention to the fact that periods of historic decay may well be times of profoundest religious insights; for historic catastrophes break the power of the idolatrous worship of cultures and civilizations. They are, or may be appropriated by faith as, divine judgements upon the inclination of men and nations to regard a tenuous and tentative form of human order or justice as the final form; or to think of the stability of a moment of history as the final peace. Thus Augustine's interpretation of Christianity was profounder, not only than the interpretations of Constantine's clerical courtiers who regarded the stability of Rome as the proof of the truth of the Christian faith, but it was also profounder than that of Thomas Aquinas, who subtly compounded the prestige of a seemingly stable clerical rule over the nations with the wisdom and the power of Christ." (Reinhold Niebuhr (1949), p. 111).

${ }^{12}$ Robert Song (2006), p. 60.

${ }^{13}$ Hirschman (2014), pp. 33-87.
} 
menos pacífico y tolerante, lo opuesto a lo establecido por los primeros liberales como Montesquieu o Tocqueville. ${ }^{14}$

Por ende, nos encontramos ante un progresismo que exige un tipo de unidad política distinto al de las primeras teorías pesimistas de la tradición moderna. Aquella visión progresista posee altas expectativas de que los males morales sean cada vez más rechazados universalmente por la humanidad a medida que avanza la historia. No obstante, aquel supuesto de la historia resulta cuestionable. Para Kant, el progreso de la humanidad, en los aspectos mencionados anteriormente, no implica necesariamente una perfección moral:

"Estamos civilizados hasta la exageración en lo que atañe a todo tipo de cortesía social y a los buenos modales. Pero para considerarnos moralizados ${ }^{15}$ queda todavía mucho. Pues si bien la idea de la moralidad forma parte de la cultura, sin embargo, la aplicación de tal idea, al restringirse a las costumbres de la honestidad y de los buenos morales externos, no deja de ser mera civilización." 16

La civilización no implica una ética ajustada al derecho, sino que consiste meramente en una cortesía social. Por tanto, el carácter moral del progreso es aparente, ya que no consiste precisamente en virtudes. No obstante, el que no se establezcan virtudes y no se defina de manera precisa lo bueno y lo malo, no implica necesariamente un relativismo cultural o una moral subjetiva. G. Graham denomina valores morales a los que permiten un acercamiento al valor objetivo de lo bueno y lo malo. Así, valores como la tolerancia, la autonomía y la igualdad humana (no respecto a lo material, sino a las libertades) se convierten en los valores que permiten este acercamiento. La búsqueda por ciertos valores morales objetivos adquiere una perspectiva falsacionista en la que la verdad depende de conjeturas y refutaciones, tal como Popper consideraba el progreso de las ciencias naturales. Por ende, las disputas y los desacuerdos deben ser tolerados, ya que permiten un acercamiento a la verdad. ${ }^{17}$ Incluso, este acercamiento hacia la verdad también se encuentra en el liberalismo clásico de S. Mill, para quien el error forma parte del proceso público para alcanzar la verdad. ${ }^{18}$ Por tanto, la pluralidad se erige como una vía para la objetividad moral y la verdad, y no tan solo como una política sobre las libertades individuales.

\footnotetext{
${ }^{14}$ Michéa (2009), p. 23.

${ }^{15}$ Ambas cursivas corresponden a la edición.

${ }^{16}$ Kant (2001), Séptimo Principio.

${ }^{17}$ Gordon Graham (1997), p. 128.

18 "La libertad completa de contradecir y desaprobar una opinión es la condición misma que nos justifica cuando la suponemos verdadera a los fines de la acción; y por ningún otro procedimiento puede el hombre llegar a tener la seguridad racional de estar en lo cierto.” John Stuart Mill (1994), p. 80.
} 
Así, el progresismo propone una nueva concepción de la perfección, en la que la doctrina egoísta se instala como el bien común de la comunidad política. Es decir, la sociedad prospera cuando cada individuo persigue su propio interés. Por este motivo, caracterizamos la actitud del progresismo como pelagiano, ya que el hombre no requiere más que de sí mismo para perfeccionarse. La teoría liberal se impone como el mejor mundo posible y como el motor de la historia de la humanidad. Esto se opone al propósito de la teoría política, el cual consistía simplemente en superar el conflicto religioso mediante la libertad de conciencia.

\section{LAS INTERPRETACIONES DE LA NEUTRALIDAD DEL MODUS VIVENDI}

En la sección anterior describimos el cambio de actitud desde la filosofía política de la tradición moderna hacia el progresismo. Aquel optimismo en la libertad individual reclama una unidad política que trasciende la coexistencia, y que espera de la sociedad una actitud comprensiva del desenvolvimiento de las libertades individuales. La teoría liberal se refiere a este tipo de convivencia como modus vivendi, mediante el cual cada individuo persigue su propia concepción de la vida buena.

Con todo, una política de este tipo no implica necesariamente una actitud omnicomprensiva entre los individuos, ni menos una perfección de la naturaleza humana. Aquella convivencia podría darse tanto de manera indiferente como benevolente. Por tanto, debemos esclarecer las diversas interpretaciones del modus vivendi.

Ahora bien, podemos intuir que, en la teoría liberal, la política del modus vivendi implica un principio neutralizador que permite sobrellevar los conflictos en una sociedad. Pero la neutralidad no posee siempre el mismo signo. Por un lado, hay posiciones pesimistas que no consideran aquella política como un medio para la perfección de los individuos ni para encontrar la verdad. Según J. Gray, el modus vivendi consiste tan solo en un recurso ante las falsas esperanzas de las filosofías que prometieron un fin en los conflictos de valor. ${ }^{19}$ Es decir, no hay ningún intento de perfección trascendente, lo que puede desembocar en una evidente indiferencia. Por el otro lado, algunas posiciones -como la de J. Horton- afirman que siempre habrá algunos valores antagonistas en una sociedad, por lo que el modus vivendi, acompañado del respeto, son la solución óptima ante aquel conflicto. ${ }^{20}$

\footnotetext{
${ }^{19}$ John Gray (2001), p. 156.

${ }^{20}$ John Horton (2011), p. 294.
} 
En esta última posición se aprecia la necesidad de algo más que la neutralidad para sobrellevar el pluralismo: la tolerancia como reconocimiento. ${ }^{21}$ Por tanto, a pesar de las discrepancias respecto a la interpretación de la neutralidad y sus efectos, la política modus vivendi no debe considerarse necesariamente como un liberalismo vacío de contenido ni como sinónimo de indiferencia. El liberalismo también puede implicar la coronación de ciertos valores. Claramente, estos no corresponden precisamente a valores morales determinados, pero permiten una base para la perfección individual, como la autonomía y la igualdad, ${ }^{22}$ y una amena convivencia social más allá del minimalismo y la indiferencia.

En la siguiente sección mostraremos de qué manera aquellos valores liberales son atribuidos a la tolerancia. Así, podremos definir la difusa línea entre la tolerancia como reconocimiento y la indiferencia.

\section{EL RESPETO O LA TOLERANCIA COMO RECONOCIMIENTO}

Luego de señalar la política modus vivendi y sus diversas interpretaciones, nos corresponde analizar el modo de la tolerancia que muestra, a partir de aquella neutralidad, un mayor acercamiento a la perfectibilidad: la tolerancia como reconocimiento o el respeto. Pero para abordar el carácter perfectible de este modo de la tolerancia, cabe formular la posibilidad de ciertas consecuencias en la sociedad abierta "liberal".

Según Michéa, en las sociedades de la actualidad el espíritu de la tolerancia es considerado como una ética substituta. Las actitudes de respeto y empatía del multiculturalismo se interpretan como signos del progreso moral de la humanidad. ${ }^{23}$ De este modo, la tolerancia como reconocimiento junto a la libertad individual representan las condiciones ideales para establecer la perfectibilidad en el liberalismo. En otras palabras, la mera garantía de las libertades individuales no basta para perfeccionar moralmente al hombre por medio de la política, sino que actitudes como el respeto y la benevolencia le otorgan una connotación moral. El mismo Michéa describe esta facilidad en la substitución de las disputas de relevancia moral, como una buena conciencia a bajo costo. ${ }^{24}$

${ }^{21}$ Esto puede ser respaldado también por el planteamiento de Rawls al afirmar que no es posible sobrellevar el conflicto mediante la mera neutralidad, ya que el balance político de fuerzas es inestable. John Rawls (2005), pp. 147-148.

${ }^{22}$ Dworkin (2000), p. 205. Al establecer un liberalismo basado en la igualdad, Dworkin distingue la neutralidad de la imparcialidad. Esto debido a que la neutralidad por sí sola no resulta equitativo para todos los individuos, generando grandes diferencias. Por tanto, para Dworkin, la neutralidad tiene sentido en cuanto que la igualdad lo requiera.

${ }^{23}$ Michéa (2009), pp. 48-49.

${ }^{24}$ Michéa (2009), p. 53. 
Uno de los efectos interesantes del respeto es la adjudicación de la palestra pública por la opinión de ciertos grupos minoritarios. Las políticas públicas de las sociedades actuales de Occidente se han enfocado en el respeto y reconocimiento de ciertos movimientos minoritarios que antes sucumbían ante la opinión hegemónica. Pero este reconocimiento no se debe a una mera tolerancia, sino a un modo de esta que la trasciende. Esto se explica, en parte, por el hecho de que la tolerancia en la esfera privada se ha trasladado al espacio público. Es decir, la tolerancia ya no se presenta solo de manera particular entre los individuos, sino que surgen políticas que se preocupan de no interferir ni oponerse a las culturas minoritarias. ${ }^{25}$ De este modo, las políticas públicas no pueden contradecir ninguna opinión, aunque esta pertenezca a la minoría, ya que equivaldría a transgredir su autonomía. ${ }^{26}$ De esta manera, el propósito de estos grupos minoritarios consiste en un progreso necesario que culmina finalmente en una ausencia de posiciones contrarias.

Algunos contemplan con recelo aquel ímpetu del progresismo moderno por la tolerancia. Michéa se refiere a su actitud altruista y tolerante como una máscara para el interés o el amor propio, al intentar mostrar aparentes convicciones morales en una doctrina egoísta. ${ }^{27} \mathrm{~T}$. Zeldin, quien también tiene una apreciación negativa, le reprocha cierta condescendencia a las políticas públicas de este tipo. Asimismo, la tolerancia como reconocimiento -afirma Zeldin-corresponde a un escalón (stepping stone), que se encuentra entre la intolerancia y algo mejor que la tolerancia. Por ende, el respeto apunta finalmente a un mundo en que hay una perfecta armonía y comprensión entre los individuos. ${ }^{28}$ La observación de este último exhibe el carácter progresista y teleológico de este modo de la tolerancia al concebirse a partir de un determinado fin: un mundo en el que no hace falta la tolerancia y todos nos comprendemos entre todos.

Aunque quienes postulan este último propósito tengan buenas intenciones, un ambiente de este tipo en el debate público puede resultar perjudicial para una sociedad. T. Bejan critica este modo de llevar la tolerancia al sostener que podría desembocar en un "silencio civil", en el que los buenos modales o la cortesía suprimen finalmente la disputa. Estos generan un ambiente en que nadie afirma nada por temor a dañar psicológica o emocionalmente a otros. Ante ello, Bejan, postula que una manera óptima de sobrellevar el conflicto no lo suprime, sino que mantiene la coexistencia de las posiciones a pesar del antagonismo de las partes,

\footnotetext{
${ }^{25}$ Fletcher (1996), p. 238.

${ }^{26}$ Idem.

${ }^{27}$ Michéa (2009), p. 90.

${ }^{28}$ Zeldin (1998), p. 272.
} 
lo que corresponde a la verdadera civilidad, en lugar de la autocensura..$^{29}$ Incluso, una sensibilización de los espacios podría llevar a una intolerancia debido a la incomunicación de las posiciones, cuyo efecto también puede ser la indiferencia.

En esta sección, el planteamiento de la tolerancia como reconocimiento y sus objeciones permite vislumbrar la posibilidad de un efecto contrario al pretendido por sus adeptos. La aproximación incuestionable y necesaria del progresismo hacia el porvenir de un mundo omnicomprensivo puede parecer difícil de reprobar. Sin embargo, los reparos recién expuestos amplían nuestra perspectiva al enseñarnos una tendencia oculta al individualismo y la indiferencia, y sus posibles efectos negativos para una sociedad. En la siguiente sección intentaremos revertir aquella apreciación negativa hacia un eventual carácter virtuoso de la tolerancia como reconocimiento, que nos permita escapar de la indiferencia y el individualismo.

\section{IV. ¿EL RESPETO A LA AUTONOMÍA COMO VIRTUD?}

En la primera sección mostramos que la perspectiva progresista de la historia no implica un progreso moral de la naturaleza humana. Aunque sí puede haber un progreso en la civilización y en la cortesía entre los individuos. Pero esto no es suficiente para determinar un acercamiento a la perfectibilidad en el progresismo moderno. Para ello, hace falta establecer virtudes que perfeccionen al hombre mediante la política. En esta parte del artículo examinaremos la posibilidad de aquella aproximación, pero a partir del elemento de la tolerancia.

A. Galeotti propone un "modelo moral" de la tolerancia, cuyo carácter se debe a que el motivo de la desaprobación es moral (la desaprobación de las elecciones morales). En ese sentido, la tolerancia como virtud moral no se presenta respecto a cualquier tipo de diferencias. ${ }^{30}$ Sin embargo, la desaprobación moral no representa necesariamente una virtud. La virtud requiere de un sacrificio de parte del sujeto, cuya acción permita la realización de un fin subsistente por sí mismo. En el caso de la tolerancia, este sacrificio se presenta al renunciar a los propios valores morales por un principio más alto. Por consiguiente, estas dos condiciones nos permiten concluir que hay ciertas acciones pertenecientes a un área gris de la moral (opiniones no condenadas universalmente), las cuales pueden ser toleradas. ${ }^{31}$

Así, la tolerancia como virtud se distingue notoriamente de la indiferencia, en cuanto que esta última consiste en una mera aceptación. En cambio, el "modelo

\footnotetext{
${ }^{29}$ Teresa M. Bejan (2017), pp. 147-54.

${ }^{30}$ Anna Elisabetta Galeotti (2001), p. 278. En el caso contrario, el campo de la tolerancia se ampliaría a los disgustos personales, perdiéndose la intención y el sacrificio moral. Esta discusión es abordada de manera más amplia por D.D. Raphael (1988), pp. 137-53.
}

${ }^{31}$ Galeotti (2001), pp. 274-275. 
moral" no puede significar aceptación, ya que aquello implica que no hay esfuerzo alguno y es inconsistente con la desaprobación de quien tolera. De este modo, la tolerancia como virtud consiste en una actitud negativa de no-interferencia, mediante la cual se toleran las decisiones guiadas por valores distintos a los propios. ${ }^{32}$

Ahora bien, cabe preguntarnos si la actitud tolerante es virtuosa al tolerar las decisiones y acciones que se establecen a partir de la autonomía. Este aspecto del problema es más profundo porque el objeto de la tolerancia ya no corresponde simplemente a la diversidad de las opiniones, sino a la persona. Es decir, toleramos al sujeto debido a su derecho a la autonomía, y no precisamente por el carácter de su opinión. Así, nos es posible distinguir entre el valor moral del agente y el de la acción. ${ }^{33}$ Por tanto, el sujeto se escinde de la acción, lo que puede resultar problemático debido a que el respeto podría tener cierto carácter de indiferencia. Esto podría contradecir una de las condiciones establecidas anteriormente sobre el "modelo moral" de la tolerancia: si el respeto recae sobre la autonomía del sujeto, entonces el motivo de la tolerancia sería indiferente a lo que él piense o haga.

Si queremos ahondar en aquella posibilidad, cabe preguntarnos ¿el agente adquiere respeto a su autonomía debido a las expectativas de sus elecciones o por el solo hecho de su capacidad para realizar elecciones libres? Respecto a la primera posición, Galleoti afirma que la autonomía no puede darse sin la integridad. ${ }^{34}$ Asimismo, C. Taylor postula que las elecciones libres deben darse por medio de una "reflexión individual", la que conlleva a una elección adecuada e íntegra. ${ }^{35}$

Las afirmaciones de Galleoti y Taylor manifiestan notoriamente el optimismo y las expectativas en torno a las elecciones libres de quien es tolerado, ya que se presupone una racionalización responsable. Así, el respeto no implica tolerar elecciones irracionales o sumidos en la ignorancia, sino que la autonomía debe ser acompañada por otros valores. Por ende, esto permite establecer una proximidad de la tolerancia como reconocimiento a la perfectibilidad, ya que se funda en actitudes con cierta pretensión de perfección, aunque esta sea mínima.

Por el contrario, respecto a concepción de la autonomía como capacidad de realizar elecciones libres, no hay expectativas en las elecciones de quien es tolerado, sino que predomina la libertad del individuo. En otras palabras, el solo hecho de que una acción se haya realizado de manera absolutamente libre es razón suficiente para ser tolerada. En este caso, hay un mayor enfoque en el modo en que

\footnotetext{
${ }^{32}$ Galeotti (2001), pp. 277.

${ }^{33}$ Galeotti (2001), p. 282. Este punto es muy discutido. Véase Sandel (1982), pp. 15-54.

${ }^{34}$ Aunque la autora sostiene, a la vez, que la capacidad de realizar acciones libres es el verdadero fundamento del respeto, cf. Galeotti (2001), pp. 282-83.
}

${ }^{35}$ Charles Taylor (1985), pp. 25-26. 
se elige, que en lo escogido. Así, esta última concepción de la autonomía tiene un carácter de indiferencia. En cambio, la primera posición, representada por Galeotti y Taylor, da cabida para una posible consideración del carácter virtuoso del respeto a la autonomía.

Con todo, aquella concepción perfeccionista de la autonomía tiene ciertos problemas en el plano práctico. ¿Cómo se desenvuelve el respeto ante el modo de vida de un individuo que no satisface las expectativas de su autonomía? Para ello, no es necesario que su vida consista en acciones universalmente condenables, sino en acciones viciosas, p. e. un fumador de dos cajetillas diarias o un obeso propenso a la comida chatarra. Ante estos casos, ¿cómo se justifica aplicar la no-interferencia de sus acciones? Claramente, el respeto no puede justificarse en todos los casos. Incluso, si lo fuese, aquello podría derivar en una actitud de indiferencia, mediante la cual se acepta cualquier acción u opinión sin escatimar en la integridad del otro.

Por tanto, si pretendemos establecer una tolerancia como virtud, es necesario establecer ciertos límites. Por un lado, aquella definición no puede ser muy restrictiva, ya que debe presuponerse que hay disputas respectos a ciertos valores morales. No obstante, por el otro, aquella tampoco puede ser tan amplia como para caer en la indiferencia.

Ante ello, cabe preguntarse: ¿cómo es posible establecer los límites del respeto sin infringir la autonomía de los demás, ni ser condescendiente con sus decisiones? Esta pregunta puede formularse también de la siguiente manera: ¿hay un compromiso pragmático de la tolerancia? Dado al objeto de este artículo, no nos corresponde abordar aquella cuestión, ni establecer límites determinados de la tolerancia. No obstante, esta última sección permite establecer ciertas directrices o posibles respuestas respecto al rol que debiese cumplir una virtud de la tolerancia. Es decir, el planteamiento del respeto como virtud conlleva a cuestionarse su rol en el plano práctico: ¿es posible establecer la virtud de la tolerancia como una política social o depende simplemente de la relación entre los individuos sin más? ${ }^{36}$ Respecto a la primera alternativa, puede resultar problemática, ya que la tolerancia adquiere rigidez y moralismo que podrían conllevar a una intolerancia. ${ }^{37}$ Sin embargo, respecto a la segunda, el enfoque de la tolerancia únicamente en la disposición de los individuos, no garantiza su realización a nivel político o social, lo que, incluso, puede llegar a la contradicción. Por tanto, pareciera haber una discontinuidad difícil

\footnotetext{
${ }^{36}$ Véase David Heyd (2008).

${ }^{37}$ Cf. Bernard Williams (1996), pp. 25-26.
} 
de revocar entre la filosofía moral y la teoría política. ${ }^{38}$ No obstante, un examen de la tolerancia como virtud contribuye a la resolución de aquel conflicto, ya que el instrumento para sobrellevar el pluralismo político adquiere un carácter moral.

\section{CONCLUSIÓN}

El propósito de este artículo consistió en mostrar un modo de la tolerancia que trascienda una mera política neutral y de carácter indiferente. La nointervención también puede tener un propósito moral dirigido a la integridad del individuo tolerado. Pero este aspecto de la tolerancia no se encuentra implícito en el progresismo moderno. Este último postula un modo de la tolerancia que consiste en un respeto a la autonomía. Pero, como lo muestra el escepticismo de Michéa, el respeto y la benevolencia no alcanzan para poseer una consciencia moral, ya que estas parecen ser, más bien, una máscara del amor propio. En ese sentido, esta apreciación de la tolerancia encaja con el optimismo en la libertad individual del progresismo moderno. Sin embargo, en la cuarta sección intentamos responder a aquella sospecha, examinando la posibilidad de una tolerancia orientada hacia la integridad, y no al amor propio.

Por ende, tolerancia no puede consistir en un mero no-intervencionismo, sino que debe apuntar a un reconocimiento de la otra posición. Este respeto o reconocimiento descansa sobre una concepción de la naturaleza humana de carácter pelagiano, en la cual el individuo se perfección a medida que persigue sus propios intereses. De este modo, la autonomía constituye un elemento fundamental del respeto. Pero, como afirmamos anteriormente, para superar la indiferencia y una interpretación individualista de la tolerancia, postulamos la posibilidad de considerar la tolerancia como una virtud, es decir, como un sacrificio con vistas a un bien. Para ello, por un lado, expusimos las distintas apreciaciones negativas que puede tener el respeto, tales como el "silencio civil" y una condescendencia que arriesga ser coactiva. Pero, por el otro, también expusimos el legítimo anhelo del progresismo por acercarnos lo más posible a un mundo en el que rija la total comprensión entre las diversas opiniones.

Podría presentarse el caso de que una mala política de la tolerancia desemboque en una indiferencia entre los ciudadanos. Pero en este artículo no abordamos aquella posibilidad, sino el respeto como una aproximación a la perfectibilidad. Por tanto, podemos concluir que aquel acercamiento depende de

\footnotetext{
${ }^{38}$ Al final de su artículo, Galeotti (2001), pp. 290-292, propone un modelo moral de la tolerancia como un puente entre la moralidad privada y la razón pública, en el que el aspecto impersonal y neutral de la política sea sobrellevado por convicciones morales no-políticas. De este modo, la política del modus vivendi no corresponde a una mera neutralidad, sino que es impulsada por la fuerza ética de la tolerancia.
} 
una adecuada consideración de la autonomía. En otras palabras, el respeto por la autonomía no consiste en el respeto por cualquier acción u opinión, sino que debemos admitir que hay ciertas formas de vida que son dañinas tanto para la comunidad como para el propio individuo. Por tanto, culminamos en una tolerancia que respeta la autonomía sin caer en la indiferencia, pero preservando, a la vez, el pluralismo de los valores. De este modo, aquella concepción de la autonomía amerita un respeto con integridad, en lugar de un mero no-intervencionismo.

Resulta necesario afirmar que nuestra pretensión no consistió en una defensa al optimismo progresista de la tolerancia, sino, más bien, en investigar la posibilidad de una tolerancia con vistas a la perfección del hombre en aquel contexto. Al final, concluimos que esa posibilidad es factible, pero no establecimos los medios para establecer la factibilidad de aquella tesis. Así, queda por establecer si aquella virtud pertenece al plano político o personal, y las características de una sociedad que permitirían establecer una relación entre aquella virtud y el progresismo moderno.

\section{BIBLIOGRAFÍA}

Bejan, Teresa M. 2017. Mere Civility: Disagreement and the Limits of Toleration. Cambridge, Massachusetts: Harvard University Press.

Castiglione, Dario \& McKinnon, Catriona. 2011. Toleration, Neutrality, and Democracy. D. Castiglione \& C. McKinnon (eds.). Dordrecht; London: Springer.

Heyd, David. 2008. “Is Toleration a Political Virtue?” Nomos 48, pp. 171-194.

Heyd, David. 1996. Toleration: An Elusive Virtue. Heyd, D. (ed.). Princeton, NJ: Princeton University Press.

De la Vieja, María Teresa Lopez. "Neutralidad liberal y valores morales", Contrastes. Revista Internacional de Filosofía 3, pp. 169-184.

Dworkin, Ronald. 2000. A Matter of Principle. 9th print. Cambridge, Massachusetts: Harvard University Press.

Fletcher, George P. "The Case for Tolerance”, Social Philosophy and Policy 13, 1, pp. 229-239. Galeotti, Anna Elisabetta. 2001. “Do We Need Toleration as a Moral Virtue?”. Res Publica 7, 3, pp. 273-92. 
Graham, Gordon (1997): "Toleration and the Idea of Progress", en Philosophy, Religion, and the Question of Intolerance, Mehdi Amin Razavi y David Ambuel (eds.), Albany: State University of New York Press.

Gray, John. 2001. Las dos caras del liberalismo: una nueva interpretación de la tolerancia liberal. Barcelona: Paidós.

Hirschman, Albert O. 2014. Las pasiones y los intereses: argumentos politicos en favor del capitalismo previos a su triunfo. Madrid: Capitán Swing.

Hobbes, Thomas. 2014. Leviatán o la materia, forma y poder de una república eclesiástica y civil. Traducido por Manuel Sánchez Sarte. México. Fondo de Cultura Económica.

Hobbes, Thomas. 2009. Tratado sobre el ciudadano. Joaquín Rodríguez Feo (ed.). Trad. por Carlos Mellizo. Madrid, España: UNED.

Horton, John. 2011. "Why the Traditional Conception of Toleration Still Matters". Critical Review of International Social and Political Philosophy 14, 3, pp. 289-305.

Cropsey, Joseph \& Strauss, Leo. 2014. Historia de la filosofía política. Cropsey, J. \& Strauss, L. (eds.). México, D.F: Fondo de Cultura Económica.

Kant, Immanuel. 2001. Ideas para una historia universal en clave cosmopolita y otros escritos sobre filosofía de la historia. Editado por Roberto Rodríguez Aramayo. Traducido por Concha Roldán Panadero. Madrid: Tecnos.

Larmore, Charles E. 1987. Patterns of Moral Complexity. Cambridge; New York: Cambridge University Press.

Locke, John. 2010. A Letter Concerning Toleration and Other Writings, trad. Mark Goldie. Indianapolis: Liberty Fund.

Mendus, Susan. 1988. Justifying Toleration: Conceptual and Historical Perspectives. Mendus, S. (ed.). Cambridge, New York: Cambridge University Press.

Michéa, Jean Claude. 2009. The Realm of Lesser Evil: An Essay on Liberal Civilization. English ed. Cambridge, UK; Malden, MA: Polity.

Mill, John Stuart. 1994. Sobre la libertad. Madrid: Alianza.

Niebuhr, Reinhold. 1949. Faith and History: A Comparison of Christian and Modern Views of History. New York: Charles Scribner's Sons.

Passmore, John Arthur. 2000. The Perfectibility of Man. (3 ${ }^{\text {rd }}$ ed.). Indianapolis: Liberty Fund. Raphael, D.D. 1988. “The Intolerable”, en: Justifying Toleration: Conceptual and Historical Perspectives, pp. 137-153. Susan Mendus (ed.) Cambridge, New York: Cambridge University Press.

Rawls, John. 2005. Political Liberalism. Columbia Classics in Philosophy. New York: Columbia University Press.

Razavi, Mehdi Amin \& David Ambuel, 1997. Philosophy, Religion, and the Question of Intolerance. Razavi, M. \& Ambuel, D. (eds.). Albany: State University of New York Press. 
Rousseau, Jean-Jacques. 2003. El contrato social o Principios de derecho politico. Traducido por Leticia Halperín Donghi. Buenos Aires: Losada.

Sandel, Michael J. 1982. Liberalism and the Limits of Justice. Cambridge, New York: Cambridge University Press.

Schelling, Friedrich Wilhelm Joseph. 2005. Sistema del idealismo trascendental. Trad. Jacinto Rivera de Rosales y Virginia Elena López Domínguez. Barcelona: Anthropos.

Song, Robert. 2006. Christianity and Liberal Society. Oxford; New York: Oxford University Press.

Spinoza, Benedictus de. 1986. Tratado político. Madrid: Alianza.

Strauss, Leo. 1989. An Introduction to Political Philosophy: Ten Essays, Hilail Gildin (ed.). Culture of Jewish modernity. Detroit: Wayne State University Press.

Taylor, Charles. 1985. Human Agency and Language. Philosophical Papers 1. Cambridge, New York: Cambridge University Press.

Zagorin, Perez. 2003. How the Idea of Religious Toleration Came to the West. Princeton, N.J: Princeton University Press.

Zeldin, Theodore. 1998. An Intimate History of Humanity. London: Vintage. 